\title{
Numerical simulation on moulded thin-walled parts via injection moulding process
}

\begin{abstract}
The current trend in the industry is to produce thin, light weight, and environmental products. In this project, flat or shallow thin-walled parts were designed and moulded lignocellulosic polymer composites (PP $+50 \mathrm{wt} \%$ wood) to visualize the processability via moulding simulation. This studied focused on the filling, shear stress at wall, and in-cavity residual stresses behaviors. The shallow thin-walled part is preferable in moulding PP + $50 \mathrm{wt} \%$ wood due to economically in processing, low shear stress distribution and low residual stresses than the flat thin-walled part.
\end{abstract}

Keyword: Fill time; In-cavity residual stresses; Injection moulding; Lignocellulosic composite; Shear stress; Thin-walled parts 